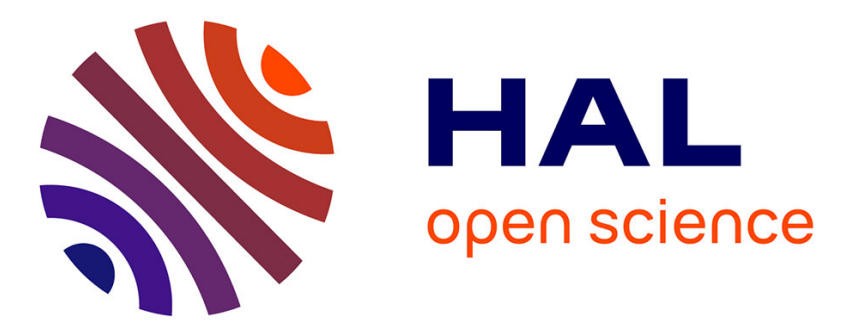

\title{
Role of the interface between the FMN and FAD domains in the control of redox potential and electronic transfer of NADPH-cytochrome $\mathrm{P} 450$ reductase
}

Louise Aigrain, Denis Pompon, Gilles Truan

\section{- To cite this version:}

Louise Aigrain, Denis Pompon, Gilles Truan. Role of the interface between the FMN and FAD domains in the control of redox potential and electronic transfer of NADPH-cytochrome P450 reductase. Biochemical Journal, 2011, 435 (1), pp.197-206. 10.1042/BJ20101984 • hal-00576992

\section{HAL Id: hal-00576992 \\ https://hal.science/hal-00576992}

Submitted on 16 Mar 2011

HAL is a multi-disciplinary open access archive for the deposit and dissemination of scientific research documents, whether they are published or not. The documents may come from teaching and research institutions in France or abroad, or from public or private research centers.
L'archive ouverte pluridisciplinaire HAL, est destinée au dépôt et à la diffusion de documents scientifiques de niveau recherche, publiés ou non, émanant des établissements d'enseignement et de recherche français ou étrangers, des laboratoires publics ou privés. 


\title{
Role of the interface between the FMN and FAD domains in the control of redox potential and electronic transfer of NADPH- cytochrome $\mathrm{P} 450$ reductase
}

\author{
Louise AIGRAIN, Denis POMPON and Gilles TRUAN ${ }^{1}$
}

Centre de Génétique Moléculaire, UPR 3404, CNRS, 1 Av. de la Terrasse, 91198, Gif-surYvette Cedex, France.

Secondary title: Effects of domain swapping on CPR properties

\begin{abstract}
NADPH cytochrome P450 reductase (CPR) is a multidomain protein containing two flavincontaining domains joined by a connecting domain supposed to control the necessary movements of the catalytic domains during electronic cycles. We present a detailed biochemical analysis of two chimeric CPR composed of the association of human or yeast FMN with the alternate connecting/FAD domains. Despite the assembly of domains having relatively large evolutionary distance between them, our data support the idea that the integrity of the catalytic cycle is conserved in our chimeric enzymes while the recognition, interactions and positioning of both catalytic domains are probably modified. The main consequences of the chimerogenesis are a decrease of the internal electron transfer rate between both flavins correlated with changes in the geometry of chimeric CPR in solution. Results presented herein highlight the role of the linker and connecting domain in the recognition at the interfaces between the catalytic domains and the impact of interdomain interactions on the redox potentials of the flavins, the internal electron transfer efficiency and the global conformation and dynamical equilibrium of the CPR.
\end{abstract}

Key words: chimeric protein, electron transfer, multidomain protein, protein interface, redox potential

\begin{abstract}
Abbreviations used: AI, aromatic interaction; CPR, NADPH-cytochrome P450 reductase; cyt c, cytochrome c; DTT, dithiothreitol; ET, electronic transfer; HB, hydrogen bond; hq, hydroquinone; HI, hydrophobic interaction; NOS, Nitric Oxide Synthase; ox, oxidized; P450, cytochrome P450; PMSF, phenylmethylsulfonyl fluoride; $\mathrm{SB}$, salt bridge; sq, semiquinone.

${ }^{1}$ To whom correspondence should be addressed (email: gilles.truan@cgm.cnrs-gif.fr)
\end{abstract}




\section{INTRODUCTION}

Multidomain proteins are usually defined as continuous polypeptide chains folded into spatially distinct structural units that are still able to perform a certain function when isolated [1]. Bioinformatics tools have facilitated domain identification in protein databases $[2,3]$, leading to the observation that $70 \%$ of eukaryotic proteins belong to multidomain protein families. The fusion of independent domains into larger units is advantageous in terms of co-localization of the components, protection of unstable species or optimization of catalytic pathways [4-7].

The NADPH-cytochrome P450 reductase (CPR) is the major redox partner for eukaryotic cytochromes P450 (P450) and belongs to the diflavin reductase family that includes the flavin domains of nitric oxide synthase (NOS) [8], methionine synthase reductase [9], NADP ${ }^{+}$-pyruvate oxidoreductase [10], cytoplasmic NR1 protein [11] or NADPH-sulfite reductase [12]. They catalyze the transfer of electrons from reduced pyridine nucleotides to a wide variety of electron acceptors with the following pathway: $\mathrm{NAD}(\mathrm{P}) \mathrm{H} \rightarrow \mathrm{FAD} \rightarrow \mathrm{FMN} \rightarrow$ acceptor [13]. CPR originates from an ancestral fusion between a flavodoxin and a ferredoxin reductase [14]. This hypothesis was further confirmed by the existence of isolated flavin domain components in prokaryotic P450 systems [15]. The union of the FMN and FAD domains is realized via a connecting domain mainly constituted of $\alpha$ helices. This connecting domain is probably meant to optimize the electronic transfer (ET) to acceptors while allowing the control of the global conformation of the enzyme $[16,17]$ and reducing the production of reactive oxygen species by protecting unstable redox species [7].

Up to 2009, the X-ray structures of rat and yeast CPR [18, 19] presented a similar spatial arrangement showing the FMN and FAD cofactors in close vicinity (closed conformation), a geometry adequate for interflavin ET. In 2009, two new conformations were characterized from the crystallographic analysis of a rat CPR mutant [20] and a yeast-human active chimera [21]. This latter protein crystallized in a widely open conformation where the FMN cofactor is completely exposed to the solvent and becomes thereby accessible to external acceptors (open conformation). The existence of alternate conformations in solution induced by redox changes and nucleotide binding was also detected by SAXS and NMR [22]. Recent ELDOR spectroscopy analysis revealed a continuum of conformational states across the energy landscape and described the nucleotide binding as a key element controlling the closing and opening of the CPR [23]. Even though the dynamical nature of CPR is now beyond doubt, the different factors (flavins redox states, presence of redox partners, cofactors binding or random oscillations) dictating such conformational switches, their modes of operation and the nature in terms of amplitude and frequencies of movements remain unclear [13, 20, 24].

Furthermore, the three dimensional structures of yeast and rat wild-type CPR cannot explain the different kinetic properties and flavin redox potentials $[24,25]$. Such properties may be governed by the various hypothetical geometrical states of each CPR in solution. Oscillating movements of the FMN domain between the FAD domain and a hemic acceptor were already postulated in other diflavin reductases such as NOS and they constitute the rate limiting step in the overall cycle of the enzyme [2628]. The crucial impact of domain recognition and the role of specific residues interactions at the interface between both flavin domains of NOS were also described [29].

To analyze how individual domains influence the overall activity of multidomain proteins, domain exchange is more appropriate than multiple site-directed mutagenesis because the simultaneous modification of several residues has often deleterious impact on the expression, folding or activity of mutant proteins. Chimerogenesis was already used to study the influence of the electron carrier part on the NOS activity by exchanging the native reductase domains of the NOS with the rat CPR [30]. Domain swapping produces a drastic interface change while leaving the core structure of each domain intact. Our approach consisted in building chimeric CPR assembled from evolutionary distant parental enzymes 
(human and yeast). We therefore analyzed the influence of domain interfaces on the various internal and external ET rates, the redox potentials of the cofactors and the global geometry of the enzymes.

\section{EXPERIMENTAL}

\section{Cloning, expression and purification}

Chimeric genes were constructed as described in [21]. Figure 1 describes the various chimeras produced and their boundaries. For soluble chimeric (HYs and YHs) and parental (Hs and Ys) CPR, genes were cloned into $\mathrm{pET} 15 \mathrm{~b}$ in frame with the 6-histidine-tag. The constructed plasmids were transformed into BL21 (DE3) competent E. coli cells to allow the expression of soluble Ys, Hs, YHs and HYs CPR. For membranous CPR (Hm, Ym, HYm, YHm), PCR products were digested, cloned into pYeDP60 vector and transformed to the CPR deficient strain WRA S. cerevisice cells [31].

Expression and purification of soluble proteins was performed as describe in [21]. Purity of the sample was determined by SDS-PAGE and spectrophotometry ( $>80 \%$, Supplementary Material, Figure $\mathrm{S} 1)$. Membranous protein expression was performed at $29^{\circ} \mathrm{C}$ in $2 \mathrm{~L}$ YPGE ( $1 \%$ Bacto Peptone, $1 \%$ yeast extract, $2 \%$ glycerol, and $2 \%$ ethanol) medium complemented by $2.5 \mathrm{mg} / \mathrm{L}$ riboflavin over 36 hours before induction by $20 \mathrm{~g} / \mathrm{L}$ of galactose over-night. Cultures were spun down for $10 \mathrm{~min}$ at $6000 \mathrm{rpm}$, washed with $200 \mathrm{~mL}$ of $\mathrm{H}_{2} \mathrm{O}$ and suspended in $200 \mathrm{~mL}$ TES (Tris $50 \mathrm{mM} \mathrm{pH} \mathrm{7.4,} \mathrm{EDTA} 10 \mathrm{mM}$, sorbitol $0.6 \mathrm{M})$ buffer. Cell lysis was achieved in TES buffer containing an antiprotease cocktail with a cell disruption system (Constant Systems Ltd). Cell debris were removed by centrifugation at 26,500 $\mathrm{g}$ for 30 min at $4{ }^{\circ} \mathrm{C}$. Microsomal proteins contained in the supernatant were precipitated by adding $0.1 \mathrm{M} \mathrm{NaCl}$ and $5 \%(\mathrm{w} / \mathrm{v})$ PEG 4000. After a centrifugation of $10 \mathrm{~min}$ at $10,000 \mathrm{rpm}$, the precipitate was resuspended in TEG buffer (50 mM Tris-HCl, $1 \mathrm{mM}$ EDTA, $20 \%(\mathrm{v} / \mathrm{v})$ glycerol, $\mathrm{pH} 7.4)$ and conserved at $-80^{\circ} \mathrm{C}$. Solubilization of membranous proteins was performed in $50 \mathrm{mM}$ Tris- $\mathrm{HCl} \mathrm{pH}$ 7.5, 20\% (v/v) glycerol, 1 mM EDTA and PMSF, $0.5 \mathrm{mM}$ DTT, $5 \mu$ M FMN and FAD, 1.25\% (v/v) Triton N-101 and 0. 625\% $(\mathrm{w} / \mathrm{v})$ sodium cholate $\mathrm{pH} 7.0$ (Buffer A) at a protein concentration of $5 \mathrm{mg} / \mathrm{mL}$ during $1 \mathrm{~h}$ at $4^{\circ} \mathrm{C}$. After a $1 \mathrm{~h}$ centrifugation at $23,000 \mathrm{rpm}$, the supernatant was applied onto a DEAE-Sepharose column equilibrated with buffer A. Fractions eluted at $0.5 \mathrm{M} \mathrm{NaCl}$ were kept, concentrated and desalted using a Vivacell-70 centrifugal concentrator (Vivasciences). Protein solutions were further purified via another affinity chromatography using a Q-Sepharose resin equilibrated with buffer A, and eluted with a $0.3 \mathrm{M}$ $\mathrm{NaCl}$ step gradient. Purity of the sample was determined by SDS-PAGE (Supplementary material, Figure S1) and examination of the $280 / 450 \mathrm{~nm}$ ratio measured by optical spectroscopy (typically 5). Membranous CPR were then concentrated to $30 \mu \mathrm{M}$ and stored at $-20^{\circ} \mathrm{C}$.

\section{Analysis of the domain interfaces of parental CPR}

Interactions at the interfaces between the FMN domain and the rest of CPR domains were determined via the internet server PIC (Protein Interaction Calculator, http://crick.mbu.iisc.ernet.in/ PIC/). Rat CPR structure was used as model for human CPR since no crystallographic structure of the human enzyme is available $(93 \%$ of sequence identity between both proteins). Interactions were detected through the distance between lateral chains of residues and classified following the type of interaction involved. Hydrophobic interactions (HI) were searched between Ala, Val, Leu, Ile, Met, Phe, Trp, Pro and Typ residues less than $5.0 \AA$ distant. Hydrogen bonds (HB) were detected when the donor-acceptor distance was less than $3.5 \AA$ and $4.0 \AA$ for oxygen/nitrogen-hydrogen and sulfur-hydrogen interactions respectively. Aromatic interactions (AI) concerned lateral chains of Lys and Arg and aromatic group of Phe, Typ or Trp less than $6 \AA$ distant. Finally, salt bridges (SB) were detected between Arg, Lys, His, Asp and Glu less than $6 \AA$ distant. The inventory of those interactions and their energies is presented in Supplementary material, Table S1. 


\section{Determination of the kinetic parameters of soluble CPR towards artificial acceptors}

Reduction of external acceptors was measured at $25^{\circ} \mathrm{C}$ in a Carry 300 spectrophotometer (Varian). Horse heart cyt $c$ reduction was followed at $550 \mathrm{~nm}\left(\varepsilon=21,000 \mathrm{M}^{-1} \cdot \mathrm{cm}^{-1}\right)$ and ferricyanide reduction at $420 \mathrm{~nm}\left(\varepsilon=1,020 \mathrm{M}^{-1} \cdot \mathrm{cm}^{-1}\right)$. CPR concentration ranged from 0.5 to $50 \mathrm{nM}$. CPR was diluted directly in a spectrophotometer cuvette containing $20 \mathrm{mM}$ sodium phosphate buffer $\mathrm{pH} 7.4$ supplemented with 0.5 units of catalase and 0.5 units of super oxide dismutase. NADPH concentration was $200 \mu \mathrm{M}$ when cyt $c$ or ferricyanide concentrations varied from 0.15 to $40 \mu \mathrm{M}$ and 3 to $400 \mu \mathrm{M}$ respectively. Cyt $c$ concentration was held at $50 \mu \mathrm{M}$ when NADPH concentration varied from 0.5 to $200 \mu \mathrm{M}$. Reactions were started by the addition of NADPH and followed during $2 \mathrm{~min}$. Experiments were repeated in triplicate. Kinetic parameters were determined by nonlinear regression using a hyperbolic function to retrieve $K_{1 / 2}$ and $V_{\max }$ values. Analyses were performed using SigmaPlot ${ }^{\mathbb{B}} 11$ (Systat Software, Inc., Chicago, US).

\section{Preparation of FMN depleted CPR}

Soluble CPR $(0.2 \mu \mathrm{M})$ were diluted in $20 \mathrm{mM}$ phosphate buffer $\mathrm{pH} 8.5,2 \mathrm{M} \mathrm{KBr}$. Bovine serum albumin saturated coal was added and the solution was gently shaken overnight at $4^{\circ} \mathrm{C}$. After centrifugation $10 \mathrm{~min}$ at $7500 \mathrm{rpm}$, supernatants were concentrated and desalted using Vivaspin-15 centrifugal concentrator (Vivasciences) to a final concentration of $6 \mu \mathrm{M}$. Saturation with either FMN of FAD was done with $6 \mu \mathrm{M}$ FMN or FAD solutions (respectively). Achievement of the saturation was assessed by cyt $c$ activity measurements.

\section{Determination of FMN and FAD contents and CPR concentration}

FAD and FMN contents were determined by HPLC analysis. Flavins were released from CPR by denaturation into $50 \mu \mathrm{L} 6 \mathrm{M}$ guanidium chloride for $10 \mathrm{~min}$ at room temperature before centrifugation 10 min at 13,200 rpm. FMN and FAD quantifications were performed by reverse phase HPLC on an XTerra ${ }^{\circledR}$ MS C18 column (Waters) using pure FAD and FMN as standards.

\section{Enzymatic reconstitution of cytochrome P450 activity}

The P450 reductase activity tests were performed in reconstituted systems made of sonicated lipidic micelles of dilauroylphosphatidylcholine $(1 \mathrm{mg} / \mathrm{ml})$ in $10 \mathrm{mM}$ MOPS buffer $\mathrm{pH}$ 7.4. Each sample contained $100 \mathrm{nM}$ human P450 3A4 (Invitrogen ${ }^{\mathrm{TM}}$ ), $30 \mathrm{mM} \mathrm{MgCl}_{2}$ and $200 \mu \mathrm{M}$ testosterone, $3 \mathrm{mM} \mathrm{GSH}$ and $200 \mathrm{nM}$ cytochrome $b_{5}$. The molar ratio of CPR versus P450 varied from 0 to 10 . The reaction was started with the addition of $2 \mathrm{mM} \mathrm{NADPH}$ and, after $30 \mathrm{~min}$ of incubation at $37^{\circ} \mathrm{C}$, the reaction was stopped by the addition of 1 volume of acetonitrile. Experiments were performed in duplicate. Testosterone and 6 6 -hydroxytestosterone quantifications were performed by reverse phase HPLC on an $\mathrm{XTerra}^{\circledR}$ MS C18 column (Waters) using pure testosterone and $6 \beta$-hydroxytestosterone as standards.

\section{Stopped-flow experiments and data processing}

Measurements of the ET rate constants were performed on a sequential SX.18MV stopped-flow coupled to a diode-array absorption spectrometer (Applied Photophysics Ltd). Experiments were carried out at room temperature in an oxygen-free phosphate buffer $20 \mathrm{mM} \mathrm{pH} \mathrm{7.4.} \mathrm{The} \mathrm{first} \mathrm{syringe} \mathrm{contained}$ the CPR solution at $20 \mu \mathrm{M}$ and the second the NADPH solution at $20 \mu \mathrm{M}$ or $200 \mu \mathrm{M}$. Before each experiment, CPR was fully oxidized by ferricyanide and desalted on a Sephadex ${ }^{\mathrm{TM}}$ G-20 (GE Healthcare). Experiments were repeated in triplicate. Data fitting and analysis were performed using SigmaPlot ${ }^{\circledR} 11$ (Systat Soft Ware, Inc., Chicago, US) with appropriate multiexponential functions (Supplementary material, Table S2): evolutions of the absorption at $455 \mathrm{~nm}$ corresponding to the biphasic flavin reduction were fitted by decreasing biexponentials, evolutions of the absorption at $585 \mathrm{~nm}$ during the first $0.25 \mathrm{~s}$ corresponding to semiquinone formation were fitted by "rise to a maximum" monoexponentials and evolutions of the absorption at $585 \mathrm{~nm}$ over $4 \mathrm{~s}$ corresponding to the first 
semiquinone formation and the further CPR reduction were analyzed as described by Guttierez \& al. [32] and fitted as by the following eq. (1):

$$
A_{5 e 5 n m}=\frac{k_{30 b s}}{k_{40 b s}-k_{30 b s}} A\left(e^{-h_{s b 2}}+e^{-h_{m b 4}}\right)+A_{0}
$$

\section{Potentiometry}

The redox titration of parental and chimeric CPR was performed under anaerobic conditions in a $100 \mathrm{mM}$ phosphate buffer $\mathrm{pH} 7.4$ that was made beforehand oxygen-free by repeated vacuum evacuation and flushing with argon purified through an Oxy-Trap column (Alltech). CPR concentration was $50 \mu \mathrm{M}$ and four mediators were added at $0.5 \mu \mathrm{M}$ to facilitate the electronic exchange between the enzyme and electrodes: safranin $\left(E^{\circ}=-280 \mathrm{mV}\right)$, phenosafranin $\left(E^{\circ}=-240 \mathrm{mV}\right)$, 2-hydroxy-1,4-naphtoquinone $\left(E^{\circ}=-\right.$ $150 \mathrm{mV})$ and benzylviologen $\left(\mathrm{E}^{\circ}=-350 \mathrm{mV}\right)$. A few units of catalase and superoxide dismutase were also added to avoid the formation of reactive oxygen species. CPR were sequentially reduced by addition of sodium dithionite aliquots and a time lapse was kept to allow the sample to reach equilibrium (assessed by the optical spectrum and solution potential stability). Absorption spectra were recorded with a Carry 300 spectrophotometer (Varian) and the solution potential was measured through an $\mathrm{Ag} / \mathrm{AgCl} / \mathrm{KCl}(210$ $\mathrm{mV} / \mathrm{SHE}$ ) reference electrode and a platinum electrode. Experiments were done in duplicate. Data were analyzed with the Electrofilter laboratory-made software based on method described previously [9, 24, $33,34]$ using eq. (2) which describe the sum of two two-electron redox processes derived by extension to the Nernst equation and the Beer-Lambert Law:

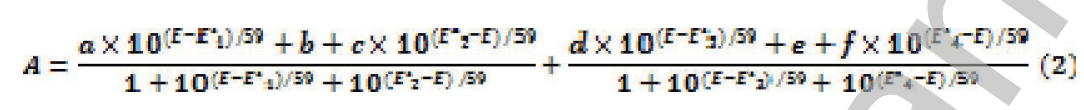

where $E^{\circ}, E_{2}^{\circ}, E^{\circ}{ }_{3}$ et $E^{\circ}{ }_{4}$ correspond respectively to the standard potentials of FMN and FAD $\mathrm{ox} / \mathrm{sq}$ and $\mathrm{sq} / \mathrm{hq}$ couples; $a-c$ are the values of the FMN extinction coefficients respectively at the oxidized, semiquinone and hydroquinone states; and $d-e$ are the same values for the FAD cofactor. The complexity of the system (4-electron titration with probable overlap of midpoint potentials) necessitated the use of a two-stage fitting process. In order to first determine the redox potentials of ox/sq couples, data recorded at $430 \mathrm{~nm}$ (isosbestic point for sq and hq forms) were fitted with the constraints $b=c$ and $e$ $=f$ since absorption coefficients for the semiquinones and reduced flavins are equal at their isosbestic point. The same argument was used to determine the redox potentials of semiquinone/reduced couples with the data at $500 \mathrm{~nm}$ (isosbestic point for oxidized and semiquinone forms, $a=b$ and $d=e$ ). Midpoint potential values obtained from the fit at isosbestic points were then used as starting points to enable accurate fitting of absorption versus reduction potential data at the maxima for oxidized flavins (455 $\mathrm{nm})$ and neutral blue semiquinone forms $(585 \mathrm{~nm})$. The oxidized flavins were assumed to have equal absorbance coefficients, specially $a=d$. [33]. Reduction potentials for the system were determined through a iterative process in which midpoint potentials associated with one isobestic point were held fixed while the other pair were varied. The process was repeated iteratively until no further change was observed [24]. Values obtained this way are similar to those originally estimated using the fit at the isobestic points (Supplementary Material, Table S3).

\section{RESULTS}

\section{Analysis of the interactions at the interfaces between CPR domains}

Domain swapping between yeast and human CPR induces a massive change of the interface between the FMN and the connecting/FAD domains. To analyze precisely the impact of this chimerogenesis on the intramolecular interactions between domains, we identified the residues involved in interdomain contacts in parental enzymes. Since no crystallographic structure of human CPR is available, we used the rat CPR as a model for the human protein (93\% sequence identity). We mapped three different regions of interaction in parental CPR (Figure 2, A and B): a first between the FMN and 
the FAD domains, a second between the FMN and the connecting domains and the last one between the FMN domain and the loop joining the connecting to the FMN domains (linker).

Conserved interactions (present in both parental enzymes) and equivalent interactions (neighbor positions in a CPR sequence alignment) should remain in the chimeric CPR (Figure 2, C and D, Table S1). They represent globally 31 and $46 \%$ of the interactions present in yeast and rat CPR respectively. On the contrary, specific interactions present in parental enzymes are most likely lost in the chimeric CPR. Since these specific interactions involve strong contact energies $(100 \%$ of the total aromatic interactions and more than $50 \%$ of the salt bridges), they probably lead to the destabilization of the closed form in $\mathrm{HY}$ and $\mathrm{YH}$, coherent with the widely open structure of YHs (Figure 2E) [21].

Around $75 \%$ interactions present at the FMN domain/linker interface are lost in the chimeras. However, a new network of side-chain interactions involving the same residues is still detectable in the open structure of YHs (Figure 2E). The reorganization of the side-chain contacts in this region may be related to a necessary control of the distance between catalytic domains during CPR domain reorganization, avoiding them to wander too far from each other and preserving a good probability of closing back the structure. In this case, the linker, which appears to be quite flexible (high B factor values in all crystal structures), should not only act as a string but also as a spring, guiding the opening and closing movement of domains.

No major modifications of the backbone structure in the connecting domain between the closed and open crystallographic structures of CPR had been detected [21], leaving unexplained the function of this connecting domain in the various suspected CPR movements. Nevertheless, by simply increasing the number of contacts, the connecting domain may favor the recognition and the positioning of the FMN and FAD domains for interflavin ET. Interactions between the FMN and the connecting domains represent indeed one third of all interactions and account for a third of their bond energy (Supplementary Information, Table S1).

The drastic modification of the interfaces between domains in our chimeric CPR leads to a considerable loss of the interactions between domains. We then question how such dramatic changes could impact CPR function.

\section{Kinetics of reduction of artificial or natural acceptors supported by chimeric and parental CPR}

To evaluate and compare the ET capabilities of the chimeric $v s$. parental CPR, kinetic parameters for the reduction of artificial acceptors (ferricyanide and cyt $c$ ) were measured (Table 1). Since the formation of a stable complex between CPR and artificial acceptors is not required for ET, half-saturation constant $K_{1 / 2}$ was used to describe this mechanism rather than the Michælis constant $K_{m}$.

Ferricyanide has the particularity to be reduced predominantly by the FAD domain $[14,35]$ while cyt $c$ behaves like a normal physiological acceptor, accepting the electrons flowing out of the FMN after an internal (FAD $\rightarrow$ FMN) ET [36]. Both YHs and HYs are still able to transfer electrons to external acceptors even though their activities are lower than those measured with parental CPR (Table 1). ET rates to ferricyanide are equivalent for parental and chimeric CPR sharing the same FAD domains (same $k_{\text {cat }}$ ferricyanide for YHs and Hs or for HYs and Ys). Therefore, the origin of the FMN domain has no effect on the ET rate from FAD to ferricyanide. However, the $K_{1 / 2}$ ferricyanide value obtained with YHs is one order of magnitude higher than the one obtained with Hs CPR, reflecting either a modification in the FAD accessibility to ferricyanide or a change in a rate limiting step occurring prior FAD $\rightarrow$ ferricyanide ET.

The $k_{\text {cat }}^{c y t}{ }^{c}$ values of HYs and YHs are respectively 10- and 15-fold lower than the human CPR $k_{\text {cat }}{ }^{c y t}{ }^{c}$ value. $K_{1 / 2}{ }^{c y t}{ }^{c}$ values are in the same order of magnitude for all CPR (between 2.4 and 3.1 $\mu \mathrm{M}$ ) with the exception of YHs which exhibit a 10 -fold lower $K_{1 / 2}{ }^{c y t} c(0.32 \mu \mathrm{M})$. Again, this change in the $K_{1 / 2}{ }^{c y t}{ }^{c}$ value could reflect either an overall change in the geometrical conformation leading to a better accessibility of the FMN domain and/or a modification in any rate limiting step occurring prior cyt $c$ 
reduction. Globally, the decrease of cyt $c$ reductase activity in the chimeras is rather due to low $k_{\text {cat }}$ values, i.e. low ET velocities.

Activities of the chimeric CPR were also measured with a natural acceptor: the human cytochrome P450 3A4 (P450-3A4). As already described, human CPR is more efficient than yeast CPR towards P450-3A4 [37] (Table 1). Interestingly, despite their low efficiencies, all soluble CPR were able to support P450 activities (approximately $15 \%$ of the activities measured with membranous CPR). This result proves that the membranous anchor of CPR is not mandatory for ET to P450 although it plays an important role in the recognition and coupling between both proteins [38]. Again, chimeric CPR are less active than parental enzymes toward P450-3A4, but the observed decrease in activities is less important when measured with P450 as an acceptor than with cyt $c$. P450 specific activities in the presence of YHm and HYm $\left(\sim 15 \mathrm{nmol} . \mathrm{min}^{-1} . \mathrm{nmol}^{-1}\right)$ are almost equivalent to the ones measured with Ym and only 3.6-fold lower than the activities measured in presence of $\mathrm{Hm}$ (Table 1). The effect of domain substitution is therefore more important on cyt $c$ reduction than on supporting P450-3A4 activity.

\section{Conservation of the electronic pathway in chimeric $C P R$}

To understand why ET from the FMN domain to acceptors for both chimeras was lowered compared to parental enzymes, we investigated the conservation of the electronic pathway in YHs and HYs. We first verified that no bimolecular ET between the FAD and FMN domains originating from two different chimeric CPR occurred. Initial cyt $c$ reduction velocity was measured as a function of CPR concentration (ranging from 0.5 to $50 \mathrm{~nm}$, Supplementary material, Figure S2). This velocity is linearly dependent on YHs or HYs concentration and the slopes are coherent with $\mathrm{k}_{\mathrm{cat}}{ }^{\mathrm{cyt} c}$ measured in steady-state kinetics experiments. This result confirms that the ET between the FMN and FAD is intramolecular and not between two different chimeric CPR.

To dismiss the possibility of a direct ET from FAD to natural or artificial acceptors, both parental and chimeric CPR were depleted from their FMN cofactor and their activities measured and compared to the initial ones (Supplementary material, Figure S3). HPLC-MS analysis confirmed that the FAD cofactor was not removed during the FMN-depleted CPR preparation. FMN depleted chimeric CPR no longer reduce cyt $c\left(\mathrm{k}_{\text {cat }}{ }^{\text {cyt }} c\right.$ are between 3 to $15 \%$ of the initial activity). YHs and HYs regain 70 to $100 \%$ of their ET capacities toward cyt $c$ when free FMN was added (2 equivalent FMN to CPR). On the contrary, addition of free FAD has absolutely no effect on the activities of either FMN-depleted or FMN-saturated chimeric CPR. Hence, the FAD domains of HYs and YHs do not promote ET to external acceptors like cyt $c$. We can therefore conclude that the electronic pathway is definitely conserved in both chimeras, with a first internal ET between the two flavins and a second external ET from the FMN to the acceptor.

\section{Rapid kinetics analysis}

To further understand the origin of the loss of cyt $c$ and $\mathrm{P} 450$ reduction activities, we analyzed, via rapid kinetic techniques, CPR reduction by NADPH. FAD reduction and internal ET from FAD to FMN were followed with a stopped-flow apparatus coupled to an absorption spectrophotometer. Flavin reduction is characterized by the diminution of the absorption at $455 \mathrm{~nm}$ (Figure $3 \mathrm{~A}, \mathrm{C}$ and E) while the interflavin ET leading to the formation of blue semiquinones is associated with an increase of the absorption around $585 \mathrm{~nm}$ (Figure 3, B, D and F and Supplementary material, Figure S4).

Fitting of the data recorded within short time ranges (0 to $25 \mathrm{~ms}$ ) (Figure 3C) allows the evaluation of the rate constants for the biphasic FAD reduction kinetic (Table 2). The first (rapid) rate constant is 1.5 times faster in chimeras than in parental CPR sharing the same FAD domain. On the contrary, the second phase is slower for both chimeras (around $1 \mathrm{~s}^{-1}$ ) compared to the yeast and human enzymes (3.4 and $7.3 \mathrm{~s}^{-1}$ respectively). An inversion of the amplitude values of the exponentials used for fitting is also observed: rapid and slow phases correspond respectively to $80 \%$ and $20 \%$ of the FAD reduction in parental CPR whereas they represent respectively around $25 \%$ and $75 \%$ of the FAD reduction in chimeras. Like yeast and human CPR, both chimeras can be distinguished by their capacity 
to be rapidly reduced by NADPH since the first rapid phase in HYs is 3.5 times higher than for YHs (Table 2).

Concerning semiquinone formation (absorption at $585 \mathrm{~nm}$ ), Ys accumulates less semiquinones than $\mathrm{Hs}$ as already described [25]. The rate of semiquinone formation is lower in chimeras compared to Hs (approximately 7 and 12 times lower for HYs and YHs respectively), but one order of magnitude greater than the rate measured for Ys. Surprisingly, after $1 \mathrm{~s}$, both chimeric enzymes have accumulated almost two times more semiquinones than Hs (Figure 3B and Table 2).

The reduction of chimeric and human CPR continues after $1 \mathrm{~s}$, leading to a further decrease of both absorptions at $455 \mathrm{~nm}$ and $585 \mathrm{~nm}$. This reduction is even greater when NADPH is added in excess (Figure 3, E and F, and Supplementary Material, Table S2) and corresponds to a second internal ET (disappearance of semiquinones) followed by a novel FAD reduction [32].

In equimolar conditions (NADPH vs. CPR), less than $10 \%$ of CPR molecules are concerned by this slow phase (Figure 3B). This proportion reaches $18 \%, 26 \%$ and $33 \%$ of YHs, HYs and the human CPR respectively when NADPH is used in 10 times excess (Figure 3F). Chimeric enzymes present the same global behavior than human CPR except that the second internal ET rate is approximately one order of magnitude lower in YHs and HYs $\left(0.13 \mathrm{~s}^{-1}\right.$ and $0.10 \mathrm{~s}^{-1}$ respectively) compared to Hs $\left(1.45 \mathrm{~s}^{-1}\right)$.

\section{Redox potentiometry}

Flavin redox potentials are characteristic of the nature of the CPR [25] and sensible to the chemical and electrostatic environment $[8,34,39]$. We have measured the effect of domain substitution on the various redox potentials of FAD and FMN species (Table 3). We used the method of Das et al. ${ }^{34}$ to fit the data obtained. This two-stage process enables an accurate evaluation of the flavin redox potentials (Supplementary Material, Table S3 and Figure S5). The theoretical fitting curves are in good agreement with the experimental data (Figure 4) except for the absorption at $500 \mathrm{~nm}$ (isosbestic point) of HYs. However, this deviation has a very low impact on the final redox potential determination since values that are first calculated with the data recorded at these isosbestic points are recalculated and refined by fitting data corresponding to the maximum absorption wavelengths (450 and $585 \mathrm{~nm}$ ) [34] for which the theoretical curve is very close to the experimental data points. Redox potentials of FAD and FMN in Hs and Ys parental CPR are in very good agreement with published values [25, 33, 40]. Redox titration experiments were repeated twice and the estimation of the error on standard redox potential values is approximately $\pm 10 \mathrm{mV}$ for $E_{1}^{\circ}, E_{2}^{\circ}$ and $E_{3}^{\circ}$ and between \pm 10 to $\pm 15 \mathrm{mV}$ for $E_{4}^{\circ}$ since the quality of spectra was slightly affected at low potentials.

The differences between $\mathrm{FAD}$ potentials $\Delta\left(E^{\circ}{ }_{3}-E^{\circ}\right)$ are in the same order of magnitude in all CPR ( 50 to $100 \mathrm{mV}$ ) and the FAD domain of HYs exhibit redox potentials that are equivalent to those of Ys and Hs. This behavior is similar to other native diflavin reductases where the FAD domain does not seem to be affected by the nature and presence of other catalytic domains [8, 9, 33]. However FAD potentials for YHs are lower than the parental ones, rendering FAD reduction by NADPH thermodynamically less favorable.

FMN standard potentials of the two chimeric CPR diverge from the values measured in parental proteins. The high $E^{\circ}$ value (around $0 \mathrm{mV}$ ) and the wide gap between $\mathrm{E}^{\circ} 1$ and $\mathrm{E}^{\circ} 2(>300 \mathrm{mV})$ clearly reflects a significant modification of the FMN environment in chimeras. The $E^{\circ}{ }_{1}$ values for YHs and $\mathrm{HYs}$ are coherent with a good stabilization of the FMN blue semiquinone giving a strong green color to YHs and HYs during their purification (data not shown) and a relatively strong accumulation of semiquinones in the stopped-flow experiments. Again, these important modifications of the FMN redox potentials probably reflect a change in the chemical environment of the flavin in the two chimeras. 


\section{DISCUSSION}

Recent progress in the description of the various factors governing the domains movements of CPR have highlighted the role of redox potential and cofactor binding [13, 20, 24]. How the various domains control the geometry of the enzyme is still under heavy investigation. The exact role of the connecting domain is still unclear because it remains structurally unchanged between the open and closed forms of CPR [20, 21]. However, a careful analysis of the interfaces between CPR domains highlights at least a static role of the connecting domain as it expands the interaction surface by a factor of $4\left(\sim 2000 \AA^{2}\right.$ compared to $500 \AA^{2}$ ). The connecting domain permits an extension of the interaction surface between the FMN and FAD domains, in contrast with class III bacterial P450 system that have smaller interaction surfaces between their redox partners. The linker itself does not present any secondary structure but the interaction network between this loop and the FMN domain avoid its complete elongation. The role of this flexible loop was also highlighted by Hamdane et al. [20]: the deletion of several residues within the linker of the rat CPR led to an enzyme that crystallized in intermediate conformations between the closed and fully open one. This deletion had also a dramatic impact on the activity of the mutants which were no longer capable of internal FAD $\rightarrow$ FMN ET. It is therefore conceivable that this flexible loop serves as a spring or rail guiding the catalytic domains during their recognition prior to internal ET.

To highlight how the domain interfaces control CPR geometry, ET rates and cofactor redox potentials, we designed chimeric enzymes substituting only the FMN domain while leaving the linker, connecting and FAD domains altogether. The biochemical characterization of HYs and YHs chimeric CPR strengthen the importance of interdomain recognition and positioning in the overall activity of CPR. The assigned role for each domain is preserved in our chimeras and the three-dimensional structure of YHs is coherent with an absence of significant backbone conformational changes in each domain in comparison with the ones from the closed conformations [21]. Kinetic analysis demonstrated that both chimeras have similar ET velocity with external acceptors. A simple model for CPR ET mechanism is presented in Figure 5.

This model describes the ET to external acceptors without the formation of any complex between CPR and the acceptor (no $\left.K_{m}\right)$. However, rapid equilibriums $\left(K_{l}\right.$ and $\left.K_{4}\right)$ followed by rate limiting elementary reaction steps (internal ET rates $k_{3}$ and $k_{6}$ ) would define cyt $c$ reduction $v s$. cyt $c$ concentration as a hyperbolic function. In such a mechanism, the decrease of the internal (FMN $\rightarrow$ FAD) ET in chimeras leads to the observed drastic decrease of $k_{c a t}{ }^{c y t} c$ values (YHs and HYs) but also in the diminution of $K_{1 / 2}{ }^{c y t c}$ (YHs). We can therefore conclude that the recognition and the ET to acceptors may not be affected in our chimeras, and that the defect in the acceptor reduction rates may only come from a decrease of the rate of internal ET.

Rapid kinetics experiments showed an inversion of the amplitudes in the rapid and slow FAD reduction phases between chimeric and parental CPR (Table 2). This behavior could be explained by different equilibrium states between several conformations adopted by the CPR in solution [22]. Some conformations could be competent for ligand binding and/or FAD reduction ( $80 \%$ of parental CPR and 20 to $30 \%$ of chimeric CPR) while the rest of the proteins would remain in an unfavorable conformation for hydride transfer ( $20 \%$ of parental and 70 to $80 \%$ of chimeric CPR). The interconversion between these conformations could constitute a rate limiting step accounting for the second (slow) FAD reduction phase [23, 41].

In a recent publication, Hay et al. [23] described the conformational landscape of the CPR geometry and the impact of interdomain distance on FAD $\rightarrow$ FMN ET efficiency. Our results confirm that interdomain interactions and internal ET are essential factors governing the ET efficiency, but also highlight that a dramatic change in the interface does not abolish domain to domain ET. The modification of the domains interactions should also lead to changes in the CPR geometry and domain mobility.

The $\mathrm{FMN}_{\mathrm{ox} / \mathrm{sq}}$ redox potentials values for YHs and HYs reveal that the FMN protonated semiquinone form is greatly stabilized, leading to a blue semiquinone even more stable than its 
mammalian counterpart. Other flavoproteins also present unusual FMN redox potentials (positive $\mathrm{E}^{\circ}$ values like HYs) [42-44]. Alterations of the FAD and the FMN redox potentials are likely to reflect a change in their chemical and electrostatic environment induced by a modification of the enzyme geometry. Several groups have pointed out the influence of cofactor binding and environmental modification on the FAD potentials and hydride transfer in diflavin reductases or ferredoxin reductases $[16,32,34,45,46]$. Surprisingly, FMN and FAD redox potentials remain almost identical in native human CPR and in isolated FMN and connecting/FAD domains "indicating that the flavins are located in discrete environments and that these environments are not significantly disrupted by genetic dissection of the domains" [33]. We should however keep in mind that potentiometry experiments are carried out in the absence of any ligand or acceptors and the measured values of flavin redox potentials originate from CPR molecules that are probably in equilibrium between several conformations. The conservation of the redox potential values of the cofactors in isolated domains and native CPR demonstrates that, in these chemical conditions, CPR adopts a flexible geometry where each domain is highly independent and probably apart from each other. In this context, the significant modifications of flavins potentials measured in our chimeric CPR may also reflect a change in the dynamical equilibrium of HYs and YHs in solution in comparison with parental CPR.

Our work confirms the essential role of the interdomain interface in controlling CPR geometry and mechanism. The surface electrostatic potentials of the two catalytic domains are well conserved across CPR from different species and even across diflavin reductases in general [47-50]. However, the biochemical properties of our chimeras demonstrate that preserving the global electrostatic potential is not sufficient to sustain a high internal ET efficiency. Our results also support the idea that the interface between FMN and connecting/FAD domains in CPR may impact the equilibrium between subpopulations.

Nucleotide binding seems to govern the closing movement since all X-ray structures of the CPR in the closed form were obtained in the presence of NADP $[18,19]$ and several biochemical analyses also support this hypothesis [23, 24, 41, 45]. The crystallographic structure of the open form of YHs in the absence of nucleotide [21] and the characterization of a dynamical equilibrium between an open and a more closed forms by SAXS analysis [22] tend to confirm that the release of the ligand is one of the factors allowing CPR opening. Other factors, notably redox states of the flavins are also suspected to promote or reflect CPR domain movements [22]. The control of the opening/closing phenomenon involve various type of effectors: some directly connected to the structure of the protein (redox potentials and interfaces) and the others being external factors (ligands, acceptors). The biochemical behavior of CPR may be the result of a combination of these various effectors. Our current hypothesis is that the binding of external effectors have a direct effect on the structure of the interface, resulting in surface modifications allowing the conformational reorganization of the CPR domains. The coupling of methods specifically designed for the study of dynamical objects such as SAXS, NMR or fluorescence spectroscopy will probably constitute a more appropriate way to further question the relationship between CPR mechanism and movements during its interactions with redox partners.

\section{REFERENCES}

1 Copley, R. R., Ponting, C. P., Schultz, J. and Bork, P. (2002) Sequence analysis of multidomain proteins: past perspectives and future directions. Adv. Protein Chem. 61, 75-98

2 Apic, G., Gough, J. and Teichmann, S. A. (2001) Domain combinations in archaeal, eubacterial and eukaryotic proteomes. J. Mol. Biol. 310, 311-325

3 Jones, S., Marin, A. and Thornton, J. M. (2000) Protein domain interfaces: characterization and comparison with oligomeric protein interfaces. Protein Eng. 13, 77-82

4 Han, J. H., Batey, S., Nickson, A. A., Teichmann, S. A. and Clarke, J. (2007) The folding and evolution of multidomain proteins. Nat. Rev. Mol. Cell Biol. 8, 319-330

5 Janin, J. and Wodak, S. J. (2002) Protein modules and protein-protein interaction. Introduction. Adv. Protein Chem. 61, 1-8 
6 Kuriyan, J. and Eisenberg, D. (2007) The origin of protein interactions and allostery in colocalization. Nature. 450, 983-990

7 Wolf, Y. I., Kondrashov, A. S. and Koonin, E. V. (2000) Interkingdom gene fusions. Genome Biology. 1, RESEARCH0013

8 Garnaud, P. E., Koetsier, M., Ost, T. W. and Daff, S. (2004) Redox properties of the isolated flavin mononucleotide- and flavin adenine dinucleotide-binding domains of neuronal nitric oxide synthase. Biochemistry. 43, 11035-11044

9 Wolthers, K. R., Basran, J., Munro, A. W. and Scrutton, N. S. (2003) Molecular dissection of human methionine synthase reductase: determination of the flavin redox potentials in full-length enzyme and isolated flavin-binding domains. Biochemistry. 42, 3911-3920

10 Rotte, C., Stejskal, F., Zhu, G., Keithly, J. S. and Martin, W. (2001) Pyruvate : NADP+ oxidoreductase from the mitochondrion of Euglena gracilis and from the apicomplexan Cryptosporidium parvum: a biochemical relic linking pyruvate metabolism in mitochondriate and amitochondriate protists. Mol. Biol. Evol. 18, 710-720

11 Kwasnicka, D. A., Krakowiak, A., Thacker, C., Brenner, C. and Vincent, S. R. (2003) Coordinate expression of NADPH-dependent flavin reductase, Fre-1, and Hint-related 7meGMP-directed hydrolase, DCS-1. J. Biol. Chem. 278, 39051-39058

12 Gruez, A., Pignol, D., Zeghouf, M., Coves, J., Fontecave, M., Ferrer, J. L. and Fontecilla-Camps, J. C. (2000) Four crystal structures of the $60 \mathrm{kDa}$ flavoprotein monomer of the sulfite reductase indicate a disordered flavodoxin-like module. J. Mol. Biol. 299, 199-212

13 Murataliev, M. B., Feyereisen, R. and Walker, F. A. (2004) Electron transfer by diflavin reductases. Biochim. Biophys. Acta. 1698, 1-26

14 Smith, G. C., Tew, D. G. and Wolf, C. R. (1994) Dissection of NADPH-cytochrome P450 oxidoreductase into distinct functional domains. Proc. Natl. Acad. Sci. U. S. A. 91, 8710-8714

15 Hannemann, F., Bichet, A., Ewen, K. M. and Bernhardt, R. (2007) Cytochrome P450 systems-biological variations of electron transport chains. Biochim. Biophys. Acta. 1770, 330-344

16 Grunau, A., Geraki, K., Grossmann, J. G. and Gutierrez, A. (2007) Conformational dynamics and the energetics of protein--ligand interactions: role of interdomain loop in human cytochrome $\mathrm{P} 450$ reductase. Biochemistry. 46, 8244-8255

17 Hawkins, A. R. and Lamb, H. K. (1995) The molecular biology of multidomain proteins. Selected examples. Eur. J. Biochem. 232, 7-18

18 Lamb, D. C., Kim, Y., Yermalitskaya, L. V., Yermalitsky, V. N., Lepesheva, G. I., Kelly, S. L., Waterman, M. R. and Podust, L. M. (2006) A second FMN binding site in yeast NADPHcytochrome P450 reductase suggests a mechanism of electron transfer by diflavin reductases. Structure. 14, 51-61

19 Wang, M., Roberts, D. L., Paschke, R., Shea, T. M., Masters, B. S. and Kim, J. J. (1997) Threedimensional structure of NADPH-cytochrome P450 reductase: prototype for FMN- and FADcontaining enzymes. Proc. Nat1. Acad. Sci. U. S. A. 94, 8411-8416

20 Hamdane, D., Xia, C., Im, S. C., Zhang, H., Kim, J. J. and Waskell, L. (2009) Structure and function of an NADPH-cytochrome P450 oxidoreductase in an open conformation capable of reducing cytochrome P450. J. Biol. Chem. 284, 11374-11384

21 Aigrain, L., Pompon, D., Morera, S. and Truan, G. (2009) Structure of the open conformation of a functional chimeric NADPH cytochrome P450 reductase. EMBO Rep. 10, 742-747

22 Ellis, J., Gutierrez, A., Barsukov, I. L., Huang, W. C., Grossmann, J. G. and Roberts, G. C. (2009) Domain motion in cytochrome P450 reductase: conformational equilibria revealed by NMR and small-angle x-ray scattering. J. Biol. Chem. 284, 36628-36637

23 Hay, S., Brenner, S., Khara, B., Quinn, A. M., Rigby, S. E. and Scrutton, N. S. (2010) Nature of the energy landscape for gated electron transfer in a dynamic redox protein. J. Am. Chem. Soc. 132, 9738-9745

24 Gutierrez, A., Munro, A. W., Grunau, A., Wolf, C. R., Scrutton, N. S. and Roberts, G. C. (2003) Interflavin electron transfer in human cytochrome P450 reductase is enhanced by coenzyme binding. Relaxation kinetic studies with coenzyme analogues. Eur. J. Biochem. 270, 2612-2621

25 Louerat-Oriou, B., Perret, A. and Pompon, D. (1998) Differential redox and electron-transfer 
properties of purified yeast, plant and human NADPH-cytochrome P-450 reductases highly modulate cytochrome P-450 activities. Eur. J. Biochem. 258, 1040-1049

26 Garcin, E. D., Bruns, C. M., Lloyd, S. J., Hosfield, D. J., Tiso, M., Gachhui, R., Stuehr, D. J., Tainer, J. A. and Getzoff, E. D. (2004) Structural basis for isozyme-specific regulation of electron transfer in nitric-oxide synthase. J. Biol. Chem. 279, 37918-37927

27 Ilagan, R. P., Tiso, M., Konas, D. W., Hemann, C., Durra, D., Hille, R. and Stuehr, D. J. (2008) Differences in a conformational equilibrium distinguish catalysis by the endothelial and neuronal nitric-oxide synthase flavoproteins. J. Biol. Chem. 283, 19603-19615

28 Stuehr, D. J., Tejero, J. and Haque, M. M. (2009) Structural and mechanistic aspects of flavoproteins: electron transfer through the nitric oxide synthase flavoprotein domain. FEBS J. 276, 3959-3974

29 Welland, A., Garnaud, P. E., Kitamura, M., Miles, C. S. and Daff, S. (2008) Importance of the domain-domain interface to the catalytic action of the NO synthase reductase domain. Biochemistry. 47, 9771-9780

30 Roman, L. J., McLain, J. and Masters, B. S. (2003) Chimeric enzymes of cytochrome P450 oxidoreductase and neuronal nitric-oxide synthase reductase domain reveal structural and functional differences. J. Biol. Chem. 278, 25700-25707

31 Truan, G., Epinat, J. C., Rougeulle, C., Cullin, C. and Pompon, D. (1994) Cloning and characterization of a yeast cytochrome b5-encoding gene which suppresses ketoconazole hypersensitivity in a NADPH-P-450 reductase-deficient strain. Gene. 142, 123-127

32 Gutierrez, A., Lian, L. Y., Wolf, C. R., Scrutton, N. S. and Roberts, G. C. (2001) Stopped-flow kinetic studies of flavin reduction in human cytochrome P450 reductase and its component domains. Biochemistry. 40, 1964-1975

33 Munro, A. W., Noble, M. A., Robledo, L., Daff, S. N. and Chapman, S. K. (2001) Determination of the redox properties of human NADPH-cytochrome P450 reductase. Biochemistry. 40, 1956-1963

34 Das, A. and Sligar, S. G. (2009) Modulation of the cytochrome P450 reductase redox potential by the phospholipid bilayer. Biochemistry. 48, 12104-12112

35 Vermilion, J. L., Ballou, D. P., Massey, V. and Coon, M. J. (1981) Separate roles for FMN and FAD in catalysis by liver microsomal NADPH-cytochrome P-450 reductase. J. Biol. Chem. 256, 266-277

36 Shen, A. L., Porter, T. D., Wilson, T. E. and Kasper, C. B. (1989) Structural analysis of the FMN binding domain of NADPH-cytochrome P-450 oxidoreductase by site-directed mutagenesis. J. Biol. Chem. 264, 7584-7589

37 Perret, A. and Pompon, D. (1998) Electron shuttle between membrane-bound cytochrome P450 3A4 and b5 rules uncoupling mechanisms. Biochemistry. 37, 11412-11424

38 Backes, W. L. and Kelley, R. W. (2003) Organization of multiple cytochrome P450s with NADPHcytochrome P450 reductase in membranes. Pharmacol. Ther. 98, 221-233

39 Batie, C. J. and Kamin, H. (1986) Association of ferredoxin-NADP+ reductase with NADP(H) specificity and oxidation-reduction properties. J. Biol. Chem. 261, 11214-11223

40 Brenner, S., Hay, S., Munro, A. W. and Scrutton, N. S. (2008) Inter-flavin electron transfer in cytochrome $\mathrm{P} 450$ reductase - effects of solvent and $\mathrm{pH}$ identify hidden complexity in mechanism. FEBS J. 275, 4540-4557

41 Gutierrez, A., Paine, M., Wolf, C. R., Scrutton, N. S. and Roberts, G. C. (2002) Relaxation kinetics of cytochrome $\mathrm{P} 450$ reductase: internal electron transfer is limited by conformational change and regulated by coenzyme binding. Biochemistry. 41, 4626-4637

42 Barber, M. J., Pollock, V. and Spence, J. T. (1988) Microcoulometric analysis of trimethylamine dehydrogenase. Biochem. J. 256, 657-659

43 Jang, M. H., Scrutton, N. S. and Hille, R. (2000) Formation of W(3)A(1) electron-transferring flavoprotein (ETF) hydroquinone in the trimethylamine dehydrogenase x ETF protein complex. J. Biol. Chem. 275, 12546-12552

44 Talfournier, F., Munro, A. W., Basran, J., Sutcliffe, M. J., Daff, S., Chapman, S. K. and Scrutton, N. S. (2001) alpha Arg-237 in Methylophilus methylotrophus (sp. W3A1) electron-transferring flavoprotein affords approximately 200-millivolt stabilization of the FAD anionic semiquinone and 
a kinetic block on full reduction to the dihydroquinone. J. Biol. Chem. 276, 20190-20196

45 Murataliev, M. B. and Feyereisen, R. (2000) Functional interactions in cytochrome P450BM3. Evidence that NADP $(\mathrm{H})$ binding controls redox potentials of the flavin cofactors. Biochemistry. 39, 12699-12707

46 Murataliev, M. B. and Feyereisen, R. (2000) Interaction of NADP(H) with oxidized and reduced P450 reductase during catalysis. Studies with nucleotide analogues. Biochemistry. 39, 5066-5074

47 Gilep, A. A., Guryev, O. L., Usanov, S. A. and Estabrook, R. W. (2001) An enzymatically active chimeric protein containing the hydrophilic form of NADPH-cytochrome P450 reductase fused to the membrane-binding domain of cytochrome b5. Biochem. Biophys. Res. Commun. 284, 937-941

48 Higashimoto, Y., Sato, H., Sakamoto, H., Takahashi, K., Palmer, G. and Noguchi, M. (2006) The reactions of heme- and verdoheme-heme oxygenase-1 complexes with FMN-depleted NADPHcytochrome P450 reductase. Electrons required for verdoheme oxidation can be transferred through a pathway not involving FMN. J. Biol. Chem. 281, 31659-31667

49 Jenkins, C. M., Genzor, C. G., Fillat, M. F., Waterman, M. R. and Gomez-Moreno, C. (1997) Negatively charged anabaena flavodoxin residues (Asp144 and Glu145) are important for reconstitution of cytochrome P450 17alpha-hydroxylase activity. J. Biol. Chem. 272, 22509-22513

50 Jenkins, C. M. and Waterman, M. R. (1998) NADPH-flavodoxin reductase and flavodoxin from Escherichia coli: characteristics as a soluble microsomal P450 reductase. Biochemistry. 37, 61066113 


\section{TABLES}

Table 1: Comparison of the specific activities and turnover numbers of chimeric and parental CPR

\begin{tabular}{|c|c|c|c|c|c|c|}
\hline & \multicolumn{3}{|c|}{ Cyt $c$ reduction } & \multicolumn{2}{|c|}{ Ferricyanide reduction } & P450 assays \\
\hline & $\begin{array}{l}k_{\mathrm{cat}}^{\mathrm{cyt} c} \\
\left(\mathrm{~s}^{-1}\right)\end{array}$ & $\begin{array}{l}K_{1 / 2}^{\text {cyt } c} \\
(\mu \mathrm{M})\end{array}$ & $\begin{array}{c}K_{m}^{\mathrm{NADPH}} \\
(\mu \mathrm{M})\end{array}$ & $\begin{array}{l}K_{l / 2}^{\text {ferricyanide }} \\
(\mu \mathrm{M})\end{array}$ & $\begin{array}{l}k_{\text {cat }}^{\text {ferricyanide }} \\
\left(\mathrm{s}^{-1}\right)\end{array}$ & $\begin{array}{c}\text { Specific activity } \\
\left(\mathrm{nmol} \cdot \mathrm{min}^{-1} \cdot \mathrm{mol}^{-1} \mathrm{P} 450\right)\end{array}$ \\
\hline $\mathrm{H}$ & $30.8 \pm 0.4$ & $3.1 \pm 0.2$ & $0.8 \pm 0.1$ & $15.2 \pm 0.5$ & $47.2 \pm 0.6$ & $53 \pm 2(11 \pm 2)$ \\
\hline Y & $149 \pm 2$ & $2.4 \pm 0.2$ & $11.6 \pm 0.6$ & $22 \pm 1$ & $116 \pm 2$ & $21 \pm 1(5 \pm 1)$ \\
\hline HY & $2.95 \pm 0.05$ & $2.5 \pm 0.2$ & $5.3 \pm 0.4$ & $13 \pm 2$ & $91 \pm 3$ & $14 \pm 1(1.9 \pm 0.4)$ \\
\hline $\mathrm{YH}$ & $1.99 \pm 0.02$ & $0.32 \pm 0.02$ & $0.05 \pm 0.01$ & $150 \pm 1$ & $45 \pm 1$ & $15 \pm 2(0.7 \pm 0.2)$ \\
\hline
\end{tabular}

Values are mean $\pm \mathrm{SD}$. Cyt $\mathrm{c}$ and ferricyanide reductions were measured with soluble proteins (Hs, Ys, HYs and YHs) while P450 assays were performed with membranous CPR (Hm, Ym, HYm, YHm).

Table 2: Apparent rate constants and amplitudes of flavin reduction and semiquinone formation in parental and chimeric CPR

\begin{tabular}{cccccc}
$\lambda(\mathrm{nm})$ & Rate constants and amplitudes & $\mathrm{Hs}$ & Ys & HYs & YHs \\
\hline \multirow{3}{*}{$455 \mathrm{~nm}$} & 43.6 & 184.7 & 276.9 & 78.2 \\
\cline { 2 - 5 } & $k_{\text {obs } 1}\left(\mathrm{~s}^{-1}\right)$ & 77 & 83 & 28 & 19 \\
\cline { 2 - 5 } & $\mathrm{A}_{1}(\%)$ & 7.3 & 3.4 & 0.8 & 1.1 \\
\cline { 2 - 5 } & $k_{\text {obs } 2}\left(\mathrm{~s}^{-1}\right)$ & 23 & 17 & 72 & 81 \\
\hline \multirow{3}{*}{$585 \mathrm{~nm}$} & $\mathrm{~A}_{2}(\%)$ & 24.7 & 0.32 & 3.4 & 2.0 \\
\cline { 2 - 6 } & $k_{\text {obs } 3}\left(\mathrm{~s}^{-1}\right)$ & 13.8 & 3.8 & 21.0 & 22.4 \\
\cline { 2 - 6 } & $\%$ semiquinones $v s$. flavins & 1.45 & - & 0.13 & 0.10 \\
\cline { 2 - 5 } & $k_{\text {obs } 4}\left(\mathrm{~s}^{-1}\right)$ & &
\end{tabular}

Experiments were repeated in triplicate with a deviation under $5 \%$. SD of the fit and R values are given in Supplementary Material, Table S3.

Table 3: Standard potentials of the flavinic redox pairs for parental and chimeric CPR

\begin{tabular}{lcccc}
\hline $\mathrm{CPR}$ & $\mathrm{E}_{1}^{\circ}$ & $\begin{array}{c}\mathrm{E}^{\circ}{ }_{2} \\
\mathrm{FMN}_{\mathrm{ox} / \mathrm{sq}}\end{array}$ & $\begin{array}{c}\mathrm{FMN}_{\mathrm{ox} / \mathrm{hq}} \\
\mathrm{FAD}_{3}\end{array}$ & $\begin{array}{c}\mathrm{E}^{\circ}{ }_{4} \\
\mathrm{FAD}_{\text {sq/hq }}\end{array}$ \\
\hline Hs & -65 & -279 & -320 & -377 \\
$\mathrm{Ys}$ & -183 & -261 & -270 & -389 \\
$\mathrm{HYs}$ & 37 & -297 & -312 & -363 \\
$\mathrm{YHs}$ & -3 & -370 & -362 & -464 \\
\hline
\end{tabular}

Potentials are given in $\mathrm{mV} / \mathrm{SHE}$. Experiments were repeated twice and errors on values are estimated to \pm $10 \mathrm{mV}$ for $E_{1}^{\circ}, E_{2}^{\circ}$ and $E^{\circ}{ }_{3}$ and between \pm 10 to $15 \mathrm{mV}$ for $E_{4}^{\circ}$. 


\section{FIGURE LEGENDS}

\section{Figure 1: Construction of the chimeric genes}

MA: membranous anchor; FMN: FMN domain; connecting + FAD: connecting and FAD domains. Numbers refer to the amino acid preceding the junction points in the wild-type full-length proteins. Domains from yeast or human CPR are indicated in white and grey colors respectively. Hs, soluble human CPR; Hm, membranous human CPR; Ys, soluble yeast CPR; Ym, membranous yeast CPR; HYs, soluble human-yeast chimeric CPR; HYm, membranous human-yeast CPR; YHs, soluble yeast-human CPR; YHm, yeast-human yeast CPR.

\section{Figure 2: Interactions between CPR domains}

A, C: rat (1J9Z); B, D: yeast (2BF4) and E: YH (3FJO) CPR. A and B: residues in dark grey, black and grey refer to the interface between FMN/FAD domains, FMN/connecting domains and FMN domain/linker respectively. C and D: residues in black represent specific interactions while residues in white represent conserved or equivalent interactions. E: residues in white spheres represent the network of interactions between the FMN domain and the linker, dotted grey and black spheres represent the conserved or equivalent interactions at the FMN domain/linker and FMN/FAD domains interfaces respectively.

\section{Figure 3: Kinetics of Hs, Ys, YHs and HYs reduction}

Squares, diamonds, circles and triangles correspond respectively to Hs, Ys, HYs and YHs. A and B show the evolution of the absorption at 455 and $585 \mathrm{~nm}$ (respectively) from 0 to $4 \mathrm{~s} ; \mathrm{C}$ and D correspond to shorter time range ( 0 to $0.25 \mathrm{~s}$ ) at the same wavelengths for equimolar ratio between CPR and NADPH. E and $\mathrm{F}$ are equivalent to $\mathrm{A}$ and $\mathrm{B}$ but with a ten times excess NADPH. Hs, filled squares; Ys, filled diamonds; HYs, filled circles; YHs, filled triangles.

\section{Figure 4: redox titration of parental and chimeric CPR}

A: Hs; B: Ys; C: HYs and D: YHs. The absorbance is plotted $v s$. the redox potential of the solution (mV $v s$. SHE) at several wavelengths. Curves $1,2,3$ and 4 correspond to the absorbance at $455 \mathrm{~nm}$ (filled triangles, oxidized flavins), $585 \mathrm{~nm}$ (filled circles, protonated semiquinones), $500 \mathrm{~nm}$ (open circles, isosbestic point between oxidized flavins and semiquinone) and $430 \mathrm{~nm}$ (open triangles, isosbestic point between semiquinones and hydroquinones). Symbols correspond to the experimental data points and solid lines represent the fitting to the four-electron Nernst equation [34].

Figure 5: Model mechanism of CPR ET during the reduction of external acceptors

$\mathrm{A}_{\text {red }}$ and $\mathrm{A}_{\mathrm{ox}}$ represents the reduced and oxidized acceptor respectively. Initial CPR species could contain either 0 electron $\left(\mathrm{FMN}_{\mathrm{ox}}\right)$ or 1 electron $\left(\mathrm{FMN}_{\mathrm{sq}}\right)$, corresponding respectively to the yeast and human stable species. 


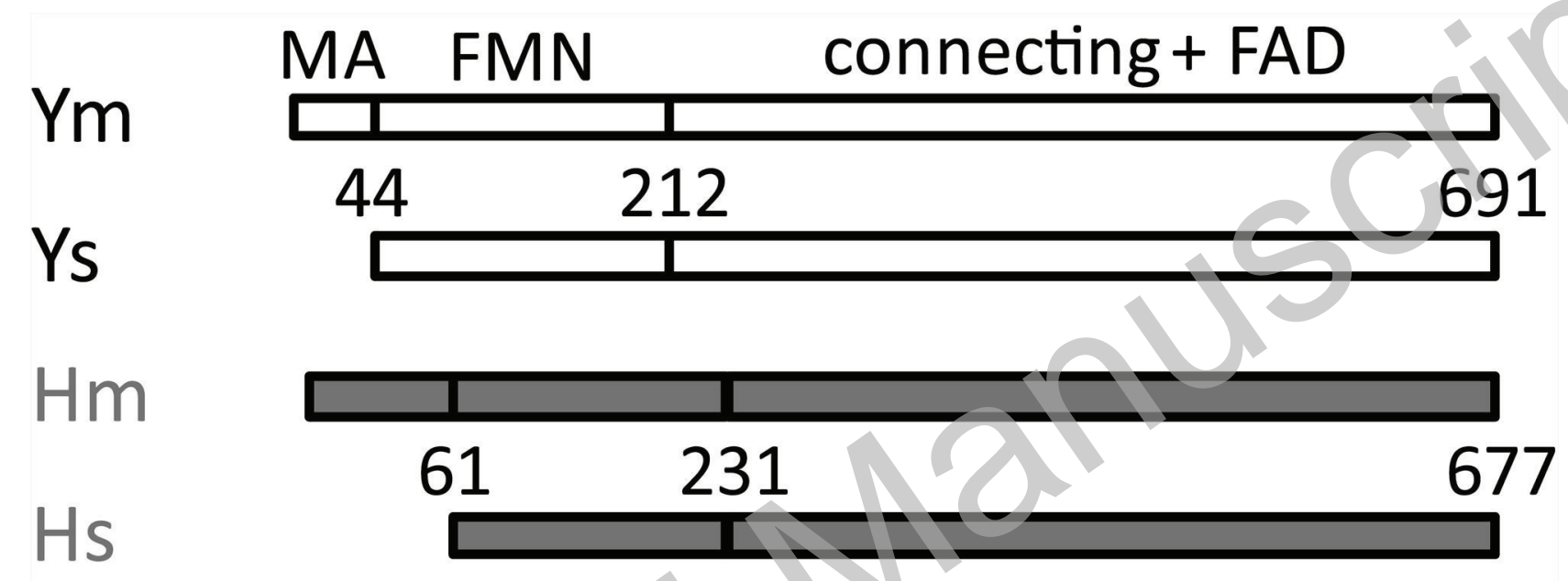

YHm

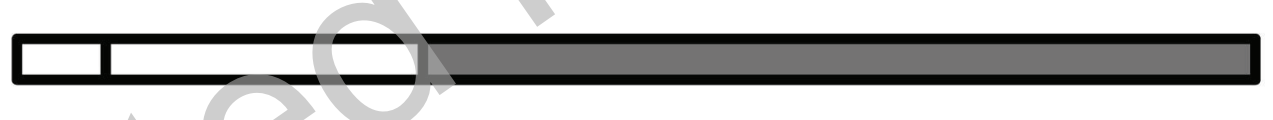

YHs
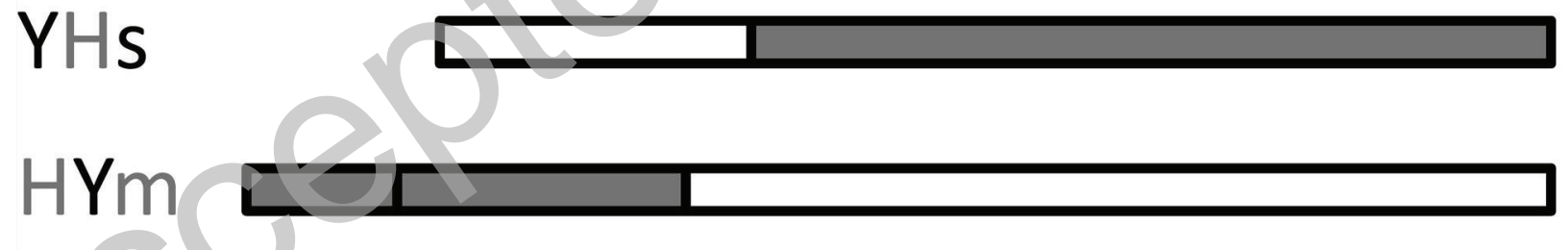

HYS 
B Biochemical Journal Immediate Publication. Published on 25 Jan 2011 as manuscript BJ20101984

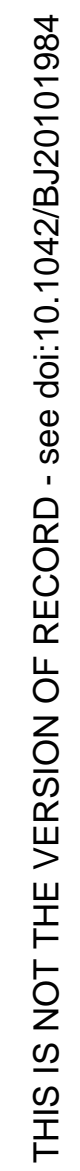
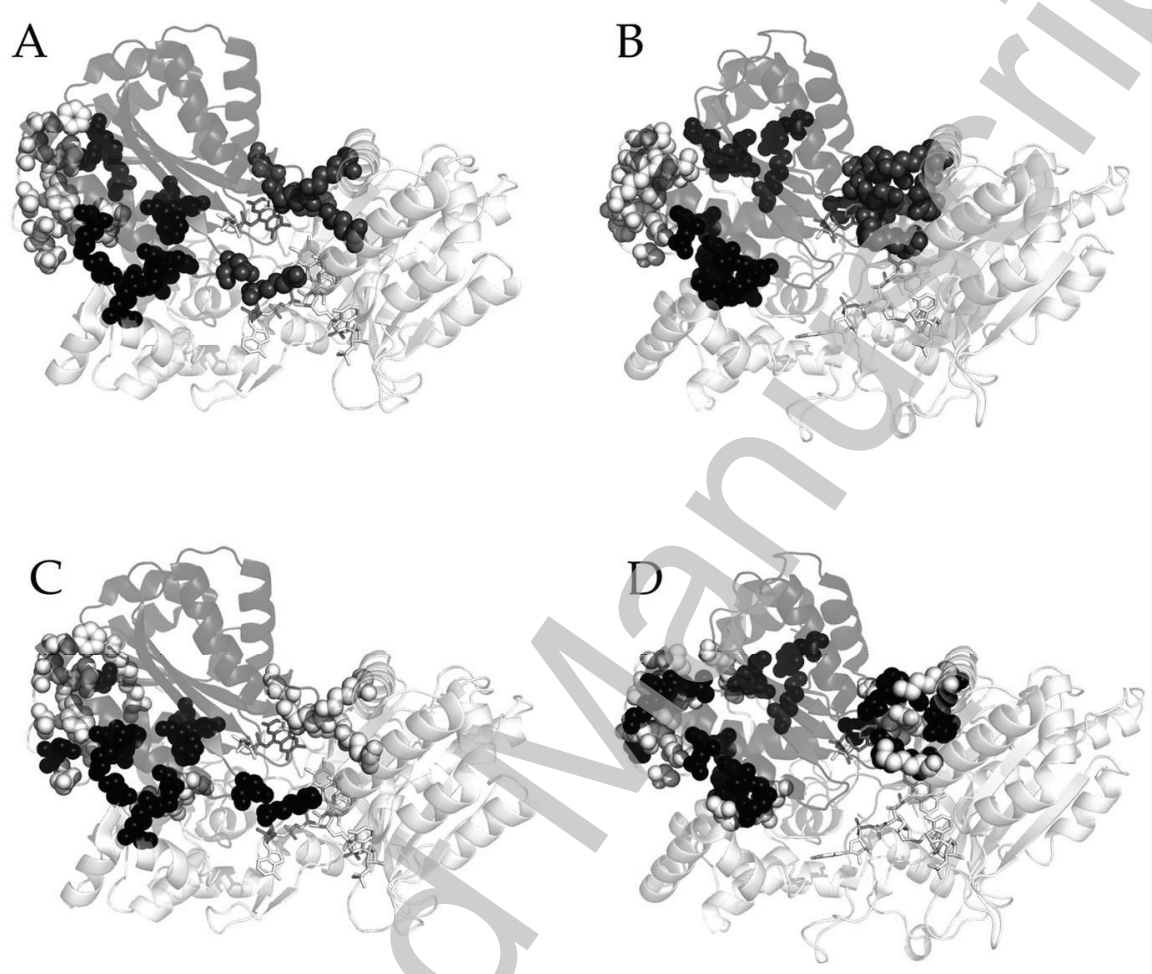

E

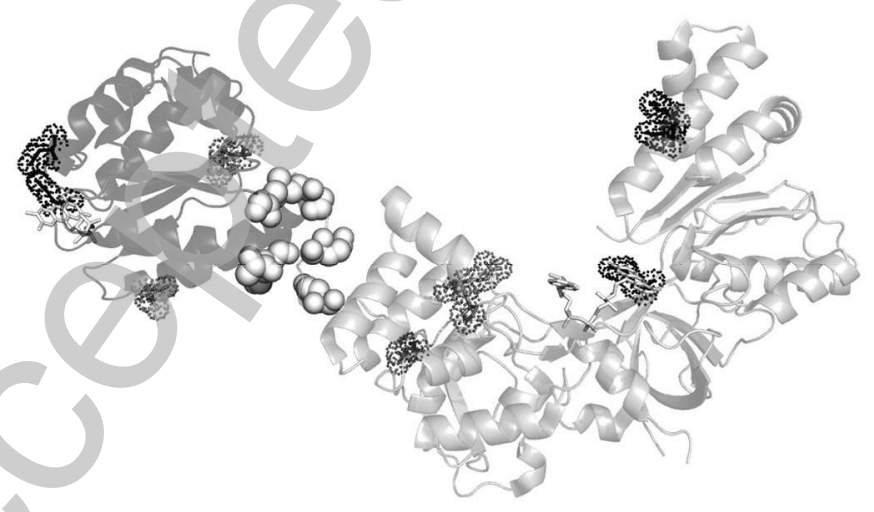

Licenced copy. Copying is not permitted, except with prior permission and as allowed by law. (C) 2011 The Authors Journal compilation (c) 2011 Portland Press Limited 
Biochemical Journal Immediate Publication. Published on 25 Jan 2011 as manuscript BJ20101984
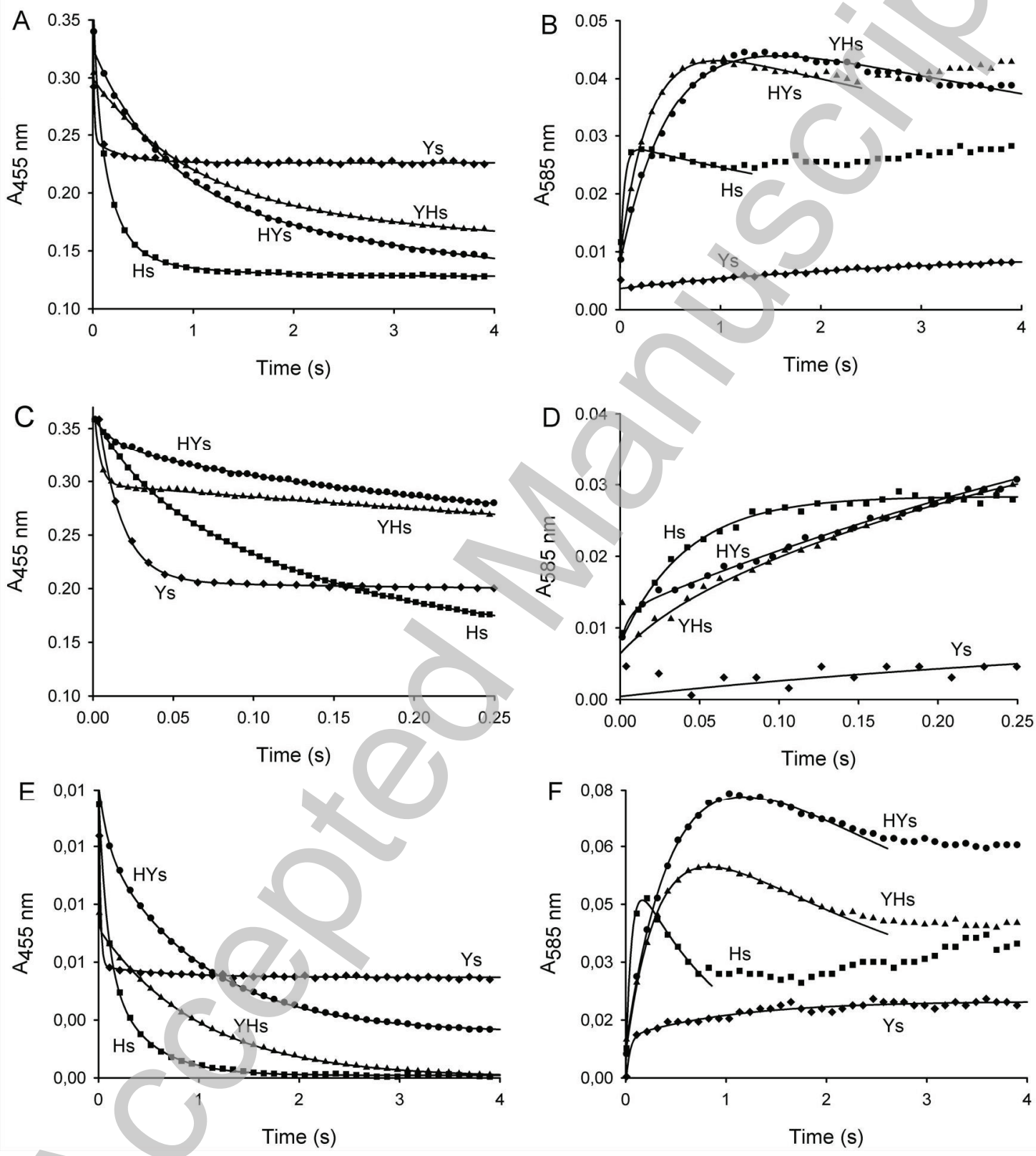

Licenced copy. Copying is not permitted, except with prior permission and as allowed by law. (c) 2011 The Authors Journal compilation (c) 2011 Portland Press Limited 
B Biochemical Journal Immediate Publication. Published on 25 Jan 2011 as manuscript BJ20101984

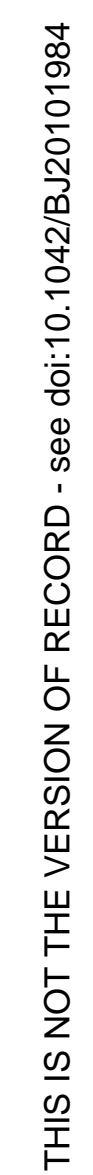
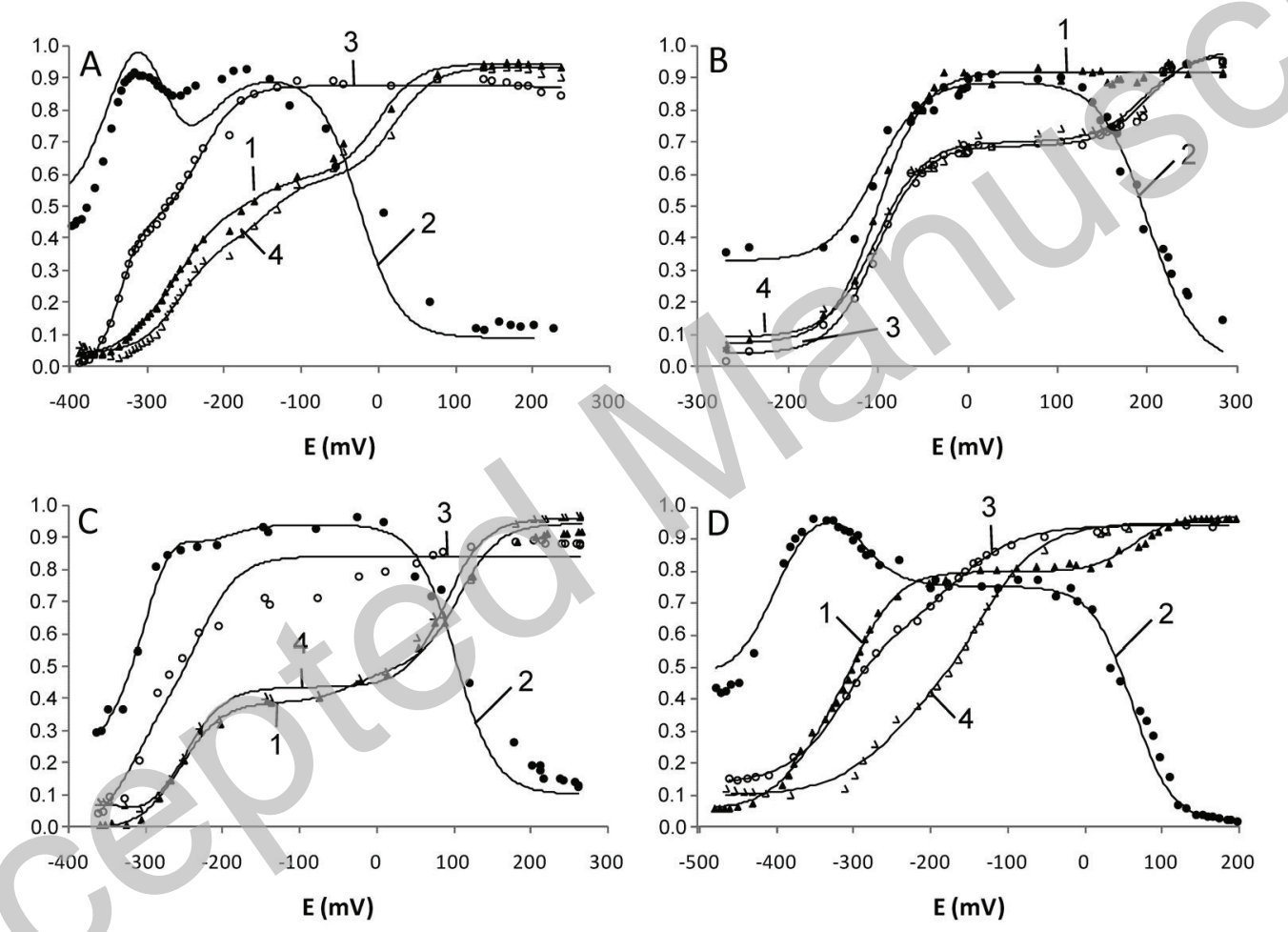


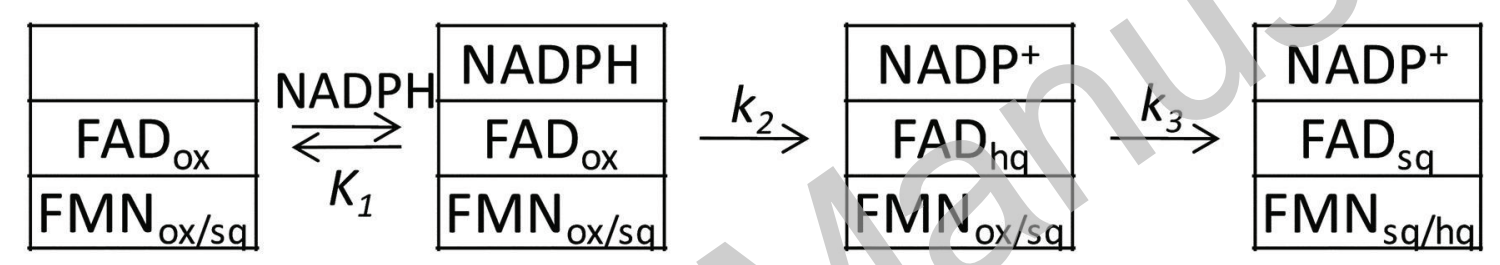
$\mathrm{A}_{\text {red }} \leftarrow \hat{\mathrm{A}_{\text {ox }}} \leqslant$ NADP $+\sqrt{\downarrow} K_{4}$

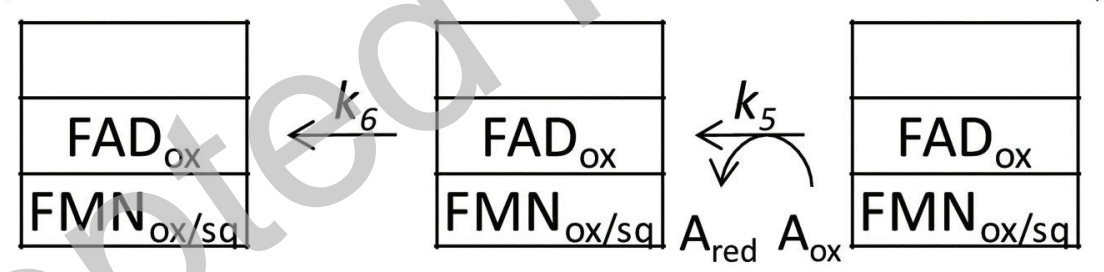

